7 Cohen $M S$, Thill JR. What causes abnormally colored urine? Contemporary Urology 1993; 8: 13-9.

8 Schoepp GH. Ostomy care and incontinence. In: Carruthers-Czyzewski P (Ed.). Self-Medication: Reference for Health Professionals, Volume 1, 4th ed. Ottawa: Canadian Pharmaceutical Association, 1992: 389.

9 Robinson DC, Millares $M$. Renal diseases. In: Herfindal ET, Gourley DR, Hart LL (Eds.). Clinical Pharmacy and Therapeutics, 4th ed. Baltimore: Williams \& Wilkins, 1988: 208.

\section{The laryngeal mask airway - a consideration for the Neonatal Resuscitation Programme guidelines?}

To the Editor:

We read with interest Dr. Elliott's excellent introduction to the Neonatal Resuscitation Programme (NRP) guidelines. ${ }^{1}$ The design of sensible, practical algorithms and their widespread dissemination is an important step in improving neonatal outcome. Airway management options included in the guidelines, however, are confined to the facemask (FM) or tracheal tube (TT). Yet bagand-mask ventilation may be wholly ineffective ${ }^{2}$ and tracheal intubation may be impossible. Neonatal airway management may be difficult, even for those with advanced airway control skills. Furthermore $80 \%$ of neonates weighing $<1.5 \mathrm{~kg}$ require resuscitation ${ }^{3}$ and airway management may be technically more difficult. Advances in neonatal airway management are rare and interest is beginning to focus on the use of the laryngeal mask airway (LMA). ${ }^{4}$

The LMA offers several advantages over the FM during neonatal resuscitation. It avoids the necessity to form a seal on a slippery surface and manipulation of the head, neck and jaw is not required. It avoids pressure to the eyes and it may free the operator to perform other tasks such as CPR or administer drugs. The advantages over the TT include avoidance of laryngoscopy and its associated adverse effects, less invasion of the respiratory tract and avoidance of the risks of endobronchial or oesophageal intubation.

An attentuated haemodynamic stress resonse to LMA insertion is likely (although unproven in neonates) and this may be important in preventing intraventricular haemorrhage. Furthermore, placement is probably independent of factors governing facial and upper airway anatomy making the LMA particularly useful in the "cannot intubate, cannot ventilate" situation in neonates. Tra- cheal intubation may also cause laryngeal oedema and in the newborn $1 \mathrm{~mm}$ of oedema reduces the crosssectional area of the larynx by $65 \% .{ }^{5}$ Potential limitations of the LMA are that it may not be suitable for removal of meconium aspirate and may be inadequate for neonates who require high airway pressures - in these situations it is not a substitute for a TT.

A large proportion of neonatal resuscitation is performed by non-medical personnel ${ }^{6}$ who are infrequently exposed to advanced resuscitation techniques and may have difficulty in maintaining proficiency. ${ }^{7}$ Tests on neonatal intubation training models have shown that midwives and junior doctors can obtain a clear airway more rapidly with the LMA than the TT and with fewer failures, ${ }^{8}$ a similar finding to adults. ${ }^{9}$ In a prospective pilot study of neonates born with apnoea or heart rate $<110 \mathrm{~min}^{-1}$, experienced LMA users were able to resuscitate 20/20 neonates with the LMA at the first attempt. ${ }^{10}$ Our experience at Cairns Base Hospital is similar and extends to $39 / 40$ successful resuscitations (unpublished data). Three of these neonates weighed 1-1.5 kg." Denny et al. used an LMA to successfully resuscitate a $2.75 \mathrm{~kg}$ neonate with Pierre-Robin syndrome in whom intubation and facemask ventilation had failed. ${ }^{12}$ Whilst large-scale studies are required to evaluate the precise role of the LMA in neonatal resuscitation and to decide what level of initial and continued training is needed, these initial results and reports are encouraging.

\section{J. Brimacombe MB ChB FRCA}

A. Berry MB ChB FRCA

Dept Anaesthesia and Intensive Care

Cairns Base Hospital

The Esplanade

Cairns 4870

Australia

\section{REFERENCES}

1 Elliott RD. Neonatal resuscitation: the NRP guidelines. Can J Anaesth 1994; 41: 742-53.

2 Milner AD, Vyas H, Hopkin I. Efficacy of facemask resuscitation at birth. Br Med J 1984; 289: 1565-5.

3 Emergency Cardiac Care Committee and Subcommittees AH. Guidelines for cardiopulmonary resuscitation and emergency cardiac care: VII. Neonatal resuscitation. JAMA 1994; 268: 2276-81.

4 Robotham $J L$. Neonatal resuscitation using the laryngeal mask airway. Anesthesiology 1994; 80: $27 \mathrm{~A}$.

5 Holinger P, Johnston $K$. Factors responsible for laryngeal obstruction in infants. JAMA 1950; 143: 1229.

6 Standards and guidelines for cardiopulmonary resuscitation (CPR) and emergency cardiac care (ECC). Part VI. Neonatal advanced life support. JAMA 1986; 255: 2969-73. 
7 Gibbs CP, Krischer J, Peckham BM, Sharp H, Kirschbaum $T H$. Obstetric anesthesia: a national survey. Anesthesiology 1986; 65: 298-306.

8 Lavies $N G$. Use of the laryngeal mask airway in neonatal resuscitation. Anaesthesia 1993; 48: 352.

9 Pennant JH, Walker MB. Comparison of the endotracheal tube and laryngeal mask in airway management by paramedical personnel. Anesth Analg 1992; 74: 531-4.

10 Paterson SJ, Byrne PJ, Molesky MG, Seal RF, Finucane $B T$. Neonatal resuscitation using the laryngeal mask airway. Anesthesiology 1994; 80: 1248-53.

11 Brimacombe J. The use of the laryngeal mask airway in very small neonates. Anesthesiology (in press).

12 Denny NM, Desilva KD, Webber PA. Laryngeal mask airway for emergency tracheostomy in a neonate. Anaesthesia $1990 ; 45: 895$. 